\title{
Prevalence of Occlusal Traits in the Deciduous Dentition of Children of Kaski District, Nepal
}

\author{
Prakash Baral,' Prakash Budathoki, ${ }^{2}$ Krishna Gopal Bhuju, ${ }^{3}$ Bandana Koirala ${ }^{4}$
}

'Anatomy department, B.P. Koirala Institute of Health Sciences, Dharan, Nepal, ${ }^{2}$ Department of prosthodontics, Kantipur Dental College, Kathmandu, Nepal, ${ }^{3}$ Dental Department, Nepal Army Medical College, Kathmandu, Nepal, ${ }^{4}$ Department of Pedodontics, B.P. Koirala Institute of Health sciences, Dharan, Nepal.

\section{ABSTRACT}

Introduction: The prevalence of occlusal traits varies among various populations. Ethnic, genetic and environmental factors are the major contributors, with a role in the specific cause of malocclusion. The aim of this epidemiological study was to assess the prevalence of occlusal traits in the deciduous dentition of children of Kaski District,Nepal.

Methods: A total of 506 children (251 girls, 255 boys), aged 3-5 years, were assessed. The occlusion examination was carried out by three examiners, in the school camps,community dental care centre and general health camps, utilizing a mouih mirror and probe. Intra investigator error was calculated using kappa statistics. The data were analyzed by the statistical program SPSS version 17 using the Chi-square test.

Results: The present study studied occlusal traits of 506 children (251 girls, 255 boys), aged 3-5 years. The study result showed that bilateral mesial step seen in $40.3 \%$,bilateral flush terminal plane in $33.5 \%$, bilateral distal steps in $8.5 \%$,mesial step one side and flush terminal other side in $12.7 \%$,mesial step one side and distal step other side in $2.6 \%$,flush terminal one side and distal step other side in $2.4 \%$, anterior crossbite in $3 \%$,posterior crossbite in $0.4 \%$ and non-spaced dentition in $20 \%$ children.

Conclusions: Mesial step was the most prevalent followed by straight terminal plane and the distal terminal plane showed least prevalence. There were diverse traits for malocclusion. There was no significant difference $(p>0.05)$ in occlusal traits between male and female children.

Keywords: crossbite; distal step; flush terminal plane; mesial step; occlusion.

\section{INTRODUCTION}

Occlusion is defined as an proper relationship between teeth of the maxillary and mandibular jaws. ${ }^{1,2}$

The prevalence of occlusal traits varies in different parts of the world among various populations. Ethnic, genetic and environmental factors are the major contributors, with a role in the specific cause of malocclusion. Knowledge about the distribution of different occlusions may help orthodontic practitioners better understand the existent problem in a geographic location and help them in the proper orientation and management of treatment possibilities. . $^{3-10}$ The need for information regarding the prevalence of occlusion in males and females and in different age and ethnic groups has provoked many studies in this respect. ${ }^{11-15}$

Correspondence: Dr. Prakash Baral, Anatomy Department, B. P. Koirala Institute of Health Sciences, Dharan, Nepal. Email : prakashbaral2002@gmail.com, Phone :+977-9804125022. 
Baral et al. Prevalence of Occlusal Traits in the Deciduous Dentition of Children of Kaski District,Nepal

It is possible to find differing prevalence rates of malocclusion in different age groups in the same population. ${ }^{16,17}$

This study was undertaken to determine the prevalence of occlusion types in 3-5 year old children of kaski district,Nepal.

\section{METHODS}

It is a cross-sectional study.Simple random sampling method was adopted for the study. A total of 506 children (251 girls, 255 boys), aged 3-5 years, were assessed. The occlusion examination was carried out by three examiners, in the school camps,community dental care centre and general health camps, utilizing a mouth mirror and probe. Intra investigator error was calculated using kappa statistics. There was no intra investigator error at all.The deciduous second molar relations i.e.Mesial,Flush and Distal terminal planes were recorded both on right and left side. Any malocclusion like,cross bite, no spacing,missing teeth,crowding, if present, were noted down. However self correcting anomalies of deciduous dentition like deep bite, spacing,etc were not considered in the study. The children with proximal caries in teeth with destruction of proximal surfaces of teeth were excluded from study. The data were analyzed by the statistical program SPSS version 17. Descriptive statistics for prevalence percentage were calculated. Chi square test was applied to test the significant difference of proportion of occlusal traits between male and female children.

\section{RESULTS}

A total of 506 children (251 girls, 255 boys), aged 3-5 years, were assessed. The occlusion examination was carried and prevalence percentage were calculated. There was no significant difference $(p>0.05)$ in occlusal traits between male and female children. Thus prevalence percentage for various types of occlusion in overall children population has been presented in the Table 1.

\begin{tabular}{|lll|}
\hline $\begin{array}{l}\text { Table } \\
\text { traits. }\end{array}$ & 1. Distribution of different types of occlusal \\
\hline SN & Occlusal traits & $\begin{array}{l}\text { Prevalence } \\
\text { Percentage }\end{array}$ \\
1. & Bilateral mesial step & 40.3 \\
2. & $\begin{array}{l}\text { Bilateral flush terminal } \\
\text { plane }\end{array}$ & 33.5 \\
3. & $\begin{array}{l}\text { Bilateral distal step } \\
\text { Mesial step one side and }\end{array}$ & $\begin{array}{l}\text { 12.5 } \\
\text { 4. }\end{array}$ \\
& $\begin{array}{l}\text { flush terminal other side } \\
\end{array}$
\end{tabular}

\begin{tabular}{|lll|} 
5. & $\begin{array}{l}\text { Mesial step one side and } \\
\text { distal step other side }\end{array}$ & 2.6 \\
6. & $\begin{array}{l}\text { Flush terminal one side and } \\
\text { distal step other side }\end{array}$ & 2.4 \\
7. & Class I Canine relation & 91.2 \\
8. & Class II Canine relation & 8.8 \\
7. & Anterior cross-bite & 3 \\
8. & $\begin{array}{l}\text { Posterior cross-bite } \\
\text { 9. }\end{array}$ & 0.4 \\
& $\begin{array}{l}\text { Non spaced dentition } \\
\text { (anterior) }\end{array}$ & 20 \\
\hline
\end{tabular}

\section{DISCUSSION}

The present study studied occlusal traits of 506 children (251 girls, 255 boys), aged 3-5 years. The occlusion examination was carried and prevalence percentage were calculated. There was no significant difference $(p>0.05)$ in occlusal traits between male and female children. The present study result showed that bilateral mesial step seen in $40.3 \%$, bilateral flush terminal plane in $33.5 \%$,bilateral distal steps in $8.5 \%$, mesial step one side and flush terminal other side in $12.7 \%$, mesial step one side and distal step other side in $2.6 \%$, flush terminal one side and distal step other side in $2.4 \%$, anterior crossbite in $3 \%$,posterior crossbite in $0.4 \%$ and non-spaced dentition in $20 \%$ children.

A study of five hundreds and twenty five of 3-4-yearold children in nursery schools and day-care centres was carried out by Otuyemi et.al to assess occlusal relationships and the presence of spacing or crowding of teeth. No significant differences in occlusal relationships were found between boys and girls $(P>0.05)$. Bilateral straight terminal planes of molars and class 1 canine relationship were the most prevalent features $174.5 \%$ and $73.3 \%$ respectively). Most of the children had 'normal' vertical and transverse occlusal relationships. The most common sites of spacing were mesial to maxillary canines and distal to mandibular canines. $32 \%$ of the children were found to have generalized anterior segment spacing, $4 \%$ showed exclusively anthropoid spaces, and $18 \%$ had either contact between all the teeth or crowding in the anterior region. ${ }^{18}$

Ferreira et, al also carried out a research on prevalence of normal occlusal traits on deciduous dentition. The aim of this research was to study the normal occlusal patterns of deciduous dentition in Brazilian preschool children. The sample consisted of 356 preschool children, of both genders, aged 3-5 1/2 years from the urban zone of Salvador, Bahia. The occlusion exam was carried out by two examiners, in the classroom, utilizing a wooden spatula. The data were analyzed by the statistical program EPI-INFO 6.02 using the Chi-squared test. The frequency of the type I arch was $43.3 \%$ for the upper 
and $46.3 \%$ for the lower arch. The frequency of the type II arch was $56.7 \%$ for the upper and 53.75 for the lower arch, however, no difference between genders was noticed. The distribution of primate spaces was: $89.9 \%$ for the upper and $67.1 \%$ for the lower arch. This prevalence decreased significantly as age increased ( $p<0.01$ ). Normal canine relationship was found in almost $60 \%$ of the children for the right and left sides. Out of 712 evaluated terminal planes, $55.9 \%$ presented mesial terminal step for the primary second molars, $37.9 \%$ straight terminal plane and $6.2 \%$ distal step. The results permitted to conclude that the presence of generalized spacing between incisors, commonly described by other authors, was not the most prevailing condition for both arches in this sample. On the other hand, primate spaces were the most common ones. The most frequent normal occlusal patterns for canine and molar relationships were found to be the Class I patterns. ${ }^{19}$

Onveaso Co had done a study in primary dentition of Nigerian children and compares the antero-posterior occlusal pattern and arch spacing in the primary dentition of Nigerian children from the 3 major ethnic groups in the country lbo, Yoruba and Hausa tribes. This is a cross-sectional epidemiological study involving eight randomly selected pre-primary schools and daycare centers in Ibadan and Lagos cities of Nigeria. Two hundred and sixty-nine 3-5-year-old children consisting of $125(46.5 \%)$ males and $144(53.6 \%)$ females were examined. A two-stage sampling method was adopted. The occlusions of the children were assessed according to the criteria by Foster and Hamilton, under natural illumination in their schools premises. Chi-square statistic was used to analyse the data. No statistically significant differences were observed in the molar and canine relationships among the ethnic groups ( $p$ $>$ 0.05). Highly statistically significant differences were noted in relation to spacing of the arches $(\mathrm{p}=$ 0.001 ) in both the anterior and posterior segments. Also, statistically significant differences were found in relation to post canine spaces $(p<0.05$ ) but not with pre-canine spaces. Spacing was found most in the Ibo ethnic group children. Although no statistically significant ethnic differences were found in the molar relationships of the study sample, very statistically significant differences were revealed in the spacing of the arches in both incisor and molar regions. ${ }^{20}$

\section{CONCLUSIONS}

The present study result showed that bilateral mesial step seen in $40.3 \%$, bilateral flush terminal plane in $33.5 \%$,bilateral distal steps in $8.5 \%$, mesial step one side and flush terminal other side in $12.7 \%$, mesial step one side and distal step other side in $2.6 \%$, flush terminal one side and distal step other side in $2.4 \%$,anterior crossbite in $3 \%$,posterior crossbite in $0.4 \%$ and nonspaced dentition in $20 \%$ children.

Thus it was concluded that mesial step was the most prevalent followed by straight terminal plane and the distal terminal plane showed least prevalence. There were diverse traits for malocclusion.There was no significant difference( $p>0.05)$ in occlusal traits between male and female children.

\section{REFERENCES}

1. Staley NR.Etiology and Prevalence of Malocclusion. In: Bishara SE. Textbook of Orthodontics. Philadelphia: Saunders; 2001: 84-104

2. Profit WR. Contemporary Orthodontics, 3rd ed. Missouri: Mosby ; 2000:2-21.

3. Wilson JR et al. Comparison of soft tissue profile changes in serial extraction and late premolar extraction. The angle orthodontist, 1999, 69(2):173-4.

4. Lloyd ZB. Serial extraction as a treatment procedure. Journal of American orthodontics, 1956, 42:728-9.

5. Moorrees CFA, Fanning EA, Gron AE. The consideration of dental development in serial extraction. The angle orthodontist, 1963, 33:44-5.

6. Odenrik L, Trocme M. Facial, dentoalveolar and dental morphology in serial or early extraction. The angle orthodontist, 1985, 55(3):206-14.

7. Ngan P, Alkire R, Fields H. Management of space problems in the primary and mixed dentitions. Journal of the American Dental Association, 1999, 130(9):1330-9.

8. Boley JC. Serial extraction revisited: 30 years in retrospect. American journal of orthodontics and dentofacial orthopedics, 2002, 121(6):575-7.

9. Bergersen EO. Preventive eruption guidance in the 5- to 7-year-old. Journal of clinical orthodontics, 1995, 29(6):382-95.

10. Staley NR.Etiology and Prevalence of Malocclusion. In: Bishara SE. Textbook of Orthodontics. Philadelphia: Saunders; 2001: 84-104. 
11. Kapila S. Distribution of malocclusions in African and Asian children in some Nairobi schools. Odontostomatol Trop 1983: 6:131-7.

12. Nganga PM. A study of occlusion anomalies and teeth loss in children aged 13-15 in Nairobi. E Afr Med J 1991; 68:980-988.

13. Ingernall B, Mohlin B, Thilender B. Prevalence and awareness of malocclusion in Swedish men. Community dent oral epidemiol. 1978:6:308-310.

14. Sazgara H, Rostami N, Maleki Z. The evaluation of occlusal interference pattern in students of Shahid Beheshti Faculty of Dentistry aged 18-25. Beheshti Univ. dent. J 1995: 20: 39-46.

15. Akhondi MS. The prevalence of malocclusions in the male students of elementary schools of Karaj. Dental Journal of Tehran Dentistry Faculty. 1996: 2: 9-19.
16. Akhondi MS. The prevalence of different malocclusions in the male students aged 11-13 in Sarab. Dental Journal of Tehran Dental Faculty 2000: 91-103.

17. Otuyemi OD,Sote EO,Isiekwe MC,Jones SP. Occlusal relationships and spacing or crowding of teeth in the dentitions of 3-4-year-old Nigerian children. Int J Paediatr Dent. 1997;7 (3): 155-160.

18. Ferreira RI, Barreira AK, Soares CD, Alves AC. Prevalence of normal occlusion traits in deciduous dentition. Pesqui Odontol Bras. $2001 ; 15(1): 23-8$.

19. 20. Onyeaso CO. Occlusion in the primary dentition. Part 1: A preliminary report on comparison of 